Original Research Paper

\title{
Why is it so Difficult to Attract FDI to the MENA Countries?
}

\author{
${ }^{1}$ Partha Gangopadhyay and ${ }^{2}$ Mohamed Elafif \\ ${ }^{I}$ Western Sydney University, Australia \\ ${ }^{2}$ Qatar University, Qatar
}

Article history

Received: 17-06-2016

Revised: 01-09-2016

Accepted: 02-09-2016

Corresponding Author:

Partha Gangopadhyay

Western Sydney University,

Australia

Email: P.Gangopadhyay@ westernsydney.edu.au

\begin{abstract}
In this study we constructively argue that the relationship between $F D I$ flows and the per capita GDP for the MENA countries has a novel feature-hitherto unrecognised-which can partially explain the great difficulty of the MENA region in attracting $F D I$. We show the existence of a separatrix, or trap, in terms of the per capita GDP: To the left of the trap, the change in the flow of $F D I$ as a percentage of GDP declines as the per capita $G D P$ rises. To the right of the trap, the change in the flow of $F D I$ as a percentage of $G D P$ rises with an increase in per capita GDP. Thus, in order to attract $F D I$, as our results show, the MENA countries must achieve a critical level of economic development in terms of the per capita GDPotherwise $F D I$ flows will be extremely sluggish. From the dataset available for 16 countries during 1996-2013, we find the per capita income trap is at US\$ 10,000 . In other words, the $F D I$ to $G D P$ ratio is a non-linear function of the per capita $G D P$ for the MENA region. In fact, we find the function to be inverse S-shaped: For per capita incomes less than $\$ 10,000$, the function is concave-as per capita $G D P$ rises, $F D I$ as a percentage of $G D P$ rises at a declining rate. Beyond this critical value of per capita GDP (trap/separatrix), the function becomes convex: As per capita GDP rises above the trap, $F D I$ as a percentage of $G D P$ then rises at an increasing rate.
\end{abstract}

Keywords: Panel Study, FDI, Per Capita GDP, Elasticity of $F D I$ with Respect to Per Capita GDP, Development Trap/Separatrix

\section{Introduction}

It is a time-honored adage that Foreign Direct Investment $(F D I)$ can promote economic growth and development in the host country by increasing the volume and productivity of investment (Borensztein et al., 1998). There is no gainsaying to the fact that FDI flows, though cyclical in nature, have been mammoth: The size of FDI flows reached a staggering level of $\$ 1,475$ billion a decade ago before the global financial crisis, which started recovering after 2011 and reached \$1.7 trillion in 2015. Despite their attempts to seek greenfield investments by creating appropriate institutions, the Middle East and North African (MENA) countries have recorded the lowest regional share (EIU, 2015, pp. 19). On an average the region attracts about $5 \%$ of the global FDI flows during the last forty years. More importantly, the resource rich countries of the MENA receive the major share of the regional FDI flows to their oil sector while the resource poor nations have been traditionally ignored by overseas investors (O'Sullivan et al., 2011). The recent political crisis in the form of the Arab Spring further accentuated the regional crisis: In late $201066 \%$ of the $\$ 64 \mathrm{~b} F D I$ to the region went to the resource rich and labour-importing nations. Within a year of the crisis, resource poor nations of the region experienced a sharp decline (46\%) in FDI flows and Ucal et al. (2010) blamed the global financial crisis for this unprecedented decline in FDI. However, Onyeiwu (2003) postulated a long-term and structural problem for the MENA countries to host FDI flows. Yet the profession is not fully convinced that there is something fundamentally wrong for the region, which is located strategically between the Western World and the powerhouse of the global economy (China and India). The major contribution of the paper is to empirically detect if the region suffers from any fundamental flaws to act as a productive host to FDI flows. This is no mean task as data for MENA countries pose a serious challenge for all researchers. Based on data availability; 16 MENA countries out of 22 have been included in this study over a period of 20 years including the incident in the form of the Arab Spring. These countries are Algeria, Egypt, Lebanon, Oman, United Arab Emirates, Bahrain, Jordan, Morocco, Syria, Saudi Arabia, Qatar, Kuwait, Iraq, Tunisia, Libya and Yemen. To the best of our 
knowledge, governance variable has not been estimated in FDI area in the MENA region especially after Arab Spring Revolutions, which is part of the period this study covers. A very interesting finding, hitherto unknown in the literature, is that the relationship between FDI flows and economic progress measured by per capita income $(G D P)$ can display a non-linear function for MENA countries, such that the intermediate levels of per capita income can act as a trap making the regional FDI flows to the MENA regions extremely sluggish. The region can only enjoy significant $F D I$ inflows only if the per capita $G D P$ exceeds the trap, which can have significant policy implications for the region.

An important, yet largely unsettled, issue is the relationship between economic development (per capita income) and FDI flows as the panel study across nations failed to provide a concrete lead due to the pooling assumption of the panel data analysis. This implicit assumption requires one to impose a common set of parameters across different nations with diverse and evolving institutional qualities that have unknown and differential impacts upon FDI flows. As a direct consequence, it is appropriate to apply the panel data analysis to understand the dynamic relationship between FDI flows and (per capita) income within a regional group of nations. This is what we seek to undertake in this study.

It is also important that one should consider a short time-horizon to reduce the possibility of abrupt and diverse changes in local institutions within the group. The objective of this paper is to understand the impacts of per capita income on the level of FDI flows in a geographic region to avoid the above pitfalls of applying the panel data analysis. To the best of our knowledge, governance, or political stability variable and nonlinear functions have not been estimated in the context of FDI in the MENA region especially after Arab Spring Revolutions, which is part of the period this study covers. We also consider a relatively short period from 1996 to 2013 to assess the relationship between FDI flows and their non-linear relationship with per capita income for the MENA region. The organization of the paper is as follows: We offer the basic model in section 2 and provide the empirical findings in section 3 and conclude in section 4 .

\section{Simple Model}

Our central concern is to examine the effects of per capita income on FDI flows for the 16 MENA countries. In this study we undertake a panel study to examine the impact of per capita income on the FDI flows for these 16 nation over a period ranging from 1996 to 2013, which will offer valuable insights into the relationship between per capita income and FDI flows in the shortrun for three sets of reasons. First and foremost, our basic idea is that individual relationships of 16 countries should have the same parameter linking per capita income to FDI flows since the levels of economic development and institutional qualities-though not homogeneous-are roughly consistent. As a result, the pooling assumption will allow us to employ the standard panel study to understand the impact of the per capita income on FDI flows in the region. Secondly and more importantly, the panel study will also enable us to overcome the problem of omitted variables. Finally, the short panel will reduce the possibility of sharp and sudden changes in the policy environment in the region.

In other words, our findings will help better understand the short-run dynamics of FDI to the region, which suggests that regulatory standards, at the early stage of development when income is low, set by national governments are relatively low and hence FDI increases sluggishly with growth in income. As income continues to rise from a low level, the priority of policy makers undergoes changes to pave institutional changes for attracting quality FDI flows. Once the income level has reached a critical threshold, policy makers take steps to ensure that FDI flows can continue unimpeded as income increases. Three basic models will be examinednamely, log linear, quadratic and cubic-to explore the shape of the relationship between per capita income $\left(Y_{i}\right)$ and FDI as a percentage of GDP flows $\left(X_{i t}\right)$ to the MENA region. Our three distinct models are as follows:

$$
\begin{aligned}
& X_{i t}=a_{1}+a_{2} \log Y_{i t}+a_{3} * \text { Control Variables } \\
& X_{i t}=a_{1}+a_{2} \log Y_{i t}+a_{3} \log Y_{i t}^{2}+a_{4} * \text { Control Variables } \\
& \left.X_{i t}=a_{1}+a_{2} \log Y_{i t}+a_{3} \log Y_{i t}\right)^{2} \\
& +a_{4}\left(\log Y_{i t}\right)^{3}+a_{5} * \text { Control Variables }
\end{aligned}
$$

Generally, the optimal $F D I$ to $G D P$ ratio $\left(X_{i t}\right)$ of a country depends on country's specific and macroeconomic factors explained by different theories in economics. The optimal FDI to GDP ratio structure can be captured for the country $i$ at time $t$ as shown in equation. Note that $X_{i t}$ labels the FDI flow as a percentage of GDP of the host country $i$ in year $t$ while $Y_{i t}$ is the per capita income of country $I$ in year $t$. Further details of the equations will be provided in section 3 .

\section{Data and Control Variables}

Our dependent variable is $(F D I / G D P)_{i t}$, or $X_{i t}$, which is the FDI to GDP ratio of country $i$ in year $t$ and $P C G D P_{\text {it }}$ is the per capita $G D P /$ income of country $\mathrm{i}$ at tear t. The control variables are the standard ones, which we choose after excluding variables with high correlation coefficients in Table 1 of the appendix. Note that $E X_{i t}$ represents the exchange rate of country $i$ in year $t, P P P_{i t}$ is the purchasing power parity of country $i$ in year $t$, 
$G D P_{i t}$ represents the real GDP of country $i$ in year $t$, $I N F_{i t}$ is the inflation rate of country $i$ in year $t, P O L R_{i t}$ represents political stability/governance of country $i$ in year $t, P O P_{i t}$ is the population of country $i$ in year $t$, $O P E N_{i t}$ is the openness index of country $i$ in year $t$ and $\varepsilon_{i t}$ is the error term in Equation 1d.

The model applied in this study has been developed to investigate intra-MENA FDI over the 1996-2013 period. The main data sources are World development Indicators, Global Governance Indicators and Pen World international (Table 1 in the appendix for definitions of variables and their measurements and data sources). Based on data availability; we choose the following countries: Algeria, Egypt, Lebanon, Oman, United Arab Emirates, Bahrain, Jordan, Morocco, Syria, Saudi Arabia, Qatar, Kuwait, Iraq, Tunisia, Libya and Yemen. To the best of our knowledge, governance/political stability variable has not been estimated in FDI area in the MENA region especially after Arab Spring Revolutions, which is part of the period this study covers.

\section{Empirical Analysis}

This section contains a brief overview of the determinants of FDI flows and regional characteristics for the MENA region during 1996-1013. The MENA countries experienced uneven growth and also fluctuating flows of FDI across different countries. As a result, significant measures have been taken by national governments to induce $F D I$ flows. For us the dependent variable (FDI flows) is called $X$ in Table 2 and measured by the logarithm of the ratio of $F D I$ to GDP. In Table 2 we represent $X$ by $L n F D I G G D$ to reflect the precise definition of the FDI flows for the econometric study. We capture the economic development of a country by the per capita GDP $(Y)$ variable, which is expressed as $L n_{-} P C G D P$. Note that economic development is the logarithm of per capita GDP in constant US dollar in Table 1. The other control variables are defined in Appendix 1. We utilise the panel data from sixteen major countries in the region from 1996 to 2013 to understand the relationship between LnFDI_GDP and Ln_PCGDP to explain the slow growth in $F \overline{I I}$ for the entire region. In total our dataset consists of 306 observations. Data on relevant variables are collected from various sources as explained in Appendix 1 in Table 1. The estimated results are summarized in Table 2 . To avoid multicollinearity we choose the lagged values of $G D P, P O L R, E X, P P P, P O P$, $O P E N$ variables, note that (L. denotes lag):

$$
\begin{aligned}
& X_{i t}=L_{n F D I} I_{-} D P_{i t}=a_{1}+a_{2} * L n_{-} P C G D P+a_{3} * \\
& \left(L n_{-} P C G D P\right)^{2}+a_{4} *\left(L n_{-} P C G D P\right)^{3}+a_{5} * L . L n G D P \\
& +a_{6} * I N F+a_{7} * L n P O P+a_{8} * L n E X+a_{9} * L n P P P \\
& +a_{10} * L n P O L R+a_{11} * L . L n \_O P E N+a_{12} * L . L X+\varepsilon_{i t}
\end{aligned}
$$

\section{FDI and Income: Basic Findings}

As discussed already, we consider the variable LnFDI_GDP to capture the flows of FDI, which is used as a proxy for $F D I$ inflows to the region while $F D I$ is widely recognized as the major source productivity growth for the region. In order to explore the dynamic effect of per capita (real) GDP on the $F D I$, this paper focuses on the linear and non-linear relationship between $L n F D I$ GDP and $L n \_P C G D P$. The link between national $F D I$ inflows and the national per capita GDP is empirically examined by means of a set of logarithmic regression models. Our argument rests on the idea that the $F D I$ varies with the level of economic development (represented by the per capita GDP) and the relationship between the two variables is non-linear-it takes the form of a wave-like pattern.

In order to better explain our results, we define the elasticity of $F D I$-to- $G D P$ ratio $(X)$ with respect to per capita $G D P(Y)$ as $\eta_{i t}$ such that:

$$
\frac{d X}{d Y}=\eta=\frac{d\left(F D I \_G D P\right) /(F D I-G D P)}{d(P C G D P) / P C G D P}
$$

Note that in Equation 2 we have ignored the time $(t)$ and country $(i)$ subscripts.

As we explore the possibility of a non-linear relationship between FDI and economic development, it is important that we allow the possibility of a quadratic or even cubic relationship. By making use of the logarithmic functional form in this study, we are able to overcome the problems associated with large order of magnitude and our results are not qualitatively affected. The estimation results are presented in Table 2.

\section{Elasticity of FDI to Per Capita Income: Some Interesting Insights}

Based on the results presented in Table 2, the estimated model (in log values) can be written as follows, where $X_{i t}$ and $Y_{i t}$ are the logarithmic transformation function to the base of 10 of the FDI to $G D P$ ratio and per capita income ( $P C G D P)$ of country $i$ in year $t$. We only explain Model 3 in what follows since all models are basically consistent and robust in showing the influence of the control variables and per capita $G D P$ :

$X_{i t}=$ Intercept $+6.30 * Y_{i t}-1.67 *\left(Y_{i t}\right)^{2}+0.14 *\left(Y_{i t}\right)^{3}$

Equation 3a can be used to derive the estimated elasticity as defined in Equation 1d as follows:

$\eta_{i t} 6.48-3.34 * Y_{i t}+0.42 *\left(Y_{i t}\right)^{2}$ 
Table 1. Variables of interest and data sources Appendix 1

\begin{tabular}{ll}
\hline Variable initial & Variable/Data source \\
\hline$F D I$ & Foreign direct investment/world development indicators $*$ \\
$G D P$ & Gross domestic production/world development Indicators* \\
$E X$ & Exchange rate/world development Indicators \\
$P P P$ & Purchasing power parity/world development Indicators \\
$I N F$ & Inflation/World development Indicators \\
$P O L R$ & Political stability/The Worldwide Governance Indicators (WGI) \\
$P C C G D P$ & Per Capita GDP $\left(Y_{i t}\right)^{*}$ \\
$L$. & Lag \\
$G M M$ & Generalized moments method \\
$P O P$ & Population in Millions \\
$O P E N$ & Openness indicator/world development indicators \\
$X_{i t}$ & Ratio of FDI to GDP \\
\hline
\end{tabular}

*: Constant US dollar

Table 2. Baseline regression with alternative formulations

\begin{tabular}{|c|c|c|c|c|c|c|}
\hline \multicolumn{7}{|c|}{ Dependent Variable $=\mathrm{X}=L n F D I \_G D P$} \\
\hline & \multicolumn{2}{|c|}{ Model 1 (FE) } & \multicolumn{2}{|c|}{ Model 2 (RE) } & Model 3 (GMM) & Model 4 (GMM) \\
\hline$\overline{L n \_P C G D P}$ & $0.083^{* * *}$ & $4.7 * * *$ & $0.063^{*}$ & $4.2 * * *$ & $6.48^{* * *}$ & $6.30 * * *$ \\
\hline $\operatorname{Ln} P C G D P^{2}$ & & $-1.17 * * *$ & & $-1.05 * * *$ & $-1.67 * * *$ & $-1.62 * * *$ \\
\hline$L n_{-}^{-} P C G D P^{3}$ & & $0.097 * * *$ & & $0.086^{* * *}$ & $0.14 * * *$ & $0.14 * * *$ \\
\hline L. $\operatorname{Ln} G D P$ & -0.004 & -0.006 & -0.008 & -0.01 & 0.0004 & \\
\hline$I N F$ & $0.108 * * *$ & $0.11 * * *$ & $0.99 * * *$ & $.10 * * *$ & $0.086^{* * *}$ & $0.08 * * *$ \\
\hline $\operatorname{LnPOP}$ & $0.024 *$ & $0.02 *$ & 0.015 & 0.01 & 0.014 & 0.009 \\
\hline $\operatorname{Ln} E X$ & 0.0028 & $0.003 *$ & 0.003 & $0.003 *$ & 0.003 & 0.002 \\
\hline L.LnPPP & -0.003 & -0.007 & -0.0025 & -0.004 & $-0.02 *$ & $0.006^{* *}$ \\
\hline $\operatorname{LnPOLR}$ & $0.006 * * *$ & $0.007 * * *$ & 0.004 & $0.005 * *$ & $0.008 * * *$ & 0.003 \\
\hline$L . X$ & & & & & $0.36 * * *$ & $0.41 * * *$ \\
\hline L.LnOPEN & $0.056 * * *$ & $0.05 * * *$ & $0.055 * * *$ & $.05 * * *$ & $0.41 * * *$ & $0.04 * * *$ \\
\hline \multirow[t]{2}{*}{ Constant } & $-0.83 * * *$ & $-4.51 *$ & $-0.38 * * *$ & $-5.7 * * *$ & & $-8.34 * * *$ \\
\hline & $\mathrm{FE}$ & $\mathrm{FE}$ & $\mathrm{RE}$ & $\mathrm{RE}$ & One Step & One Step \\
\hline Adjusted R-square & 0.30 & 0.32 & 0.28 & 0.30 & & \\
\hline
\end{tabular}

Hausman test Accept FE estimation.

Accept FE estimation.

Note: ${ }^{*}, * * * *$ are significant at 10,5 and 1\% levels, respectively. FE: Fixed Effect, Re: Random Effect, GMM: SGMM: L: The lag operator, Ln: Logarithmic transformation

The change in elasticity $\eta_{i t}$ with respect to $Y_{i t}$ $\left(L n \_P C G D P_{i t}\right)$, ignoring the time and country subscripts, can be written as:

$$
d_{\eta} / d Y=\Omega=-3.34+0.84 * Y
$$

Equation $3 b$ suggests that the elasticity is not fixed. The relationship between the elasticity of FDI and per capita income depends on the level of economic development level, i.e., per capita GDP. The effect is strongly reflected in the estimated cubic models. Equation 3 c suggests that a $1 \%$ increase in $L n \_P C G D P$ in a country in the MENA region causes $0.84 \%$ increase in the increase in the rate of FDI flows measured by $\Omega$. However, if the per capita income is static, then $\Omega$ declines by -3.34 ceteris paribus. This gives us the critical value of Ln_PCGDP $(=X=3.97)$ till which $\Omega$ declines. Beyond this critical value, $\Omega$ increases. Thus the per capita $G D P$ of $\$ 10,000$ acts as a trap, which lowers the change in the elasticity of FDI to the PCGDP as the PCGDP rises for
$P C G D P<\$ 10,000$. Beyond $\$ 10,000$, as the $P C G D P$ rises, so does the elasticity of inflow of $F D I$ with respect to the per capita $G D P$. Figure 1 illustrates the relationship given by Equation $3 \mathrm{c}$ such that $O Y^{*}$ is the trap in terms of $P C G D P(=\$ 10,000)$. Schedule $A A^{\prime}$ describes the $U$-shaped relationship between $\Omega$ and $P C G D P(Y)$. The change in elasticity of $F D I$ as a percentage of $G D P$ with respect to $P C G D P(\Omega)$ decreases for $P C G D P<\$ 10,000$ as $P C G D P$ rises. On the other hand, for $P C G D P>\$ 10,000, \Omega$ rises as $P C G D P$ increases.

In a similar vein Fig. 2 describes the concave-convex relationship $\left(L L^{\prime}\right)$ between $\eta$ and PCGDP $(Y): L L^{\prime}$ is concave till the per capita income trap $\left(O Y^{*}\right)$ such that as $P C G D P(Y)$ increases, the elasticity of $(\eta)$ increases as a decreasing rate. Beyond the trap, $P C G D P>\$ 10,000, \eta$ rises at an increasing rate for increases in $P C G D P$.

For the control variables, we observe the following: (i) we note that the FDI-to-GDP ratio in the MENA countries can be explained by the lagged values of the level of economic development measured by the per capita $G D P$ $(P C G D P)$. (ii) Purchasing Power Parity $(P P P)$ variable has 
impacts that are uncertain. (iii) the lagged value of $(\log )$ $G D P$ that does not seem to have any statistically significant effect on the FDI flows in the MENA region. Thus, the market size does not seem to exert significant influence on FDI flows. (iv) it is instructive to note that macroeconomic variables like inflation $(I N F)$, quality of political regime/governance $(P O L R)$, openness indicator $(O P E N)$, accelerate the pace of $F D I$ mobility to the region-as expected. (v) though the size of population ( $L n P O P)$ seems to enhance the FDI flows, yet the statistical significance is not always observed. This, once again, suggests that the size of market does not seem to play an important role in determining FDI flows for the MENA countries.

As the results establish, our main contributions to the literature are three fold: First, we show the existence of a separatrix, or trap, in terms of the per capita GDP, which is labelled as as $Y^{*}$ in Fig. 1. This trap creates nonlinearities in the relationship between $\Omega$ and $Y$ (Fig. 1).

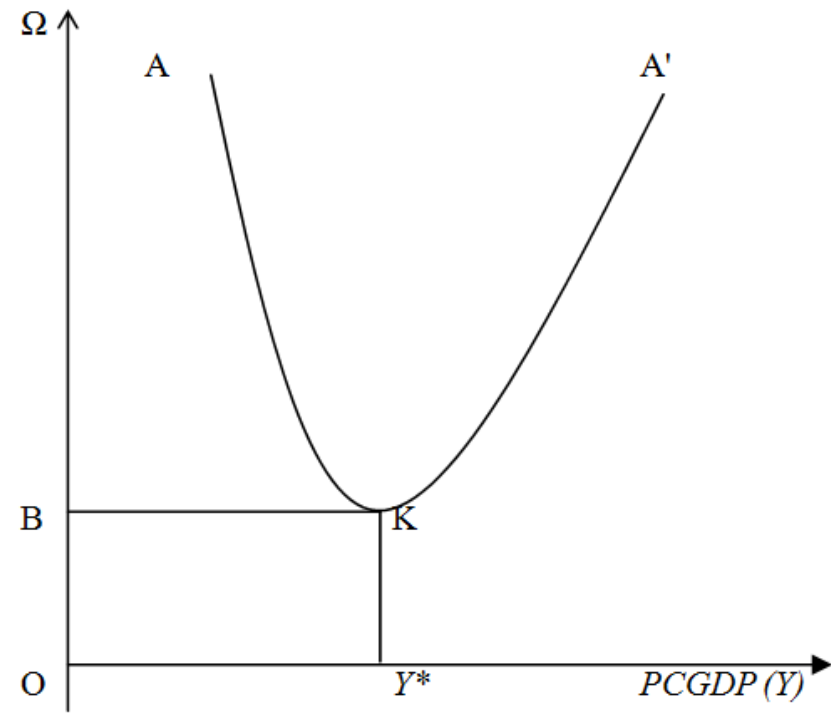

Fig. 1. The Dynamics of $\Omega$ and the per capita $G D P(P C G D P)$ : U-shaped relationship

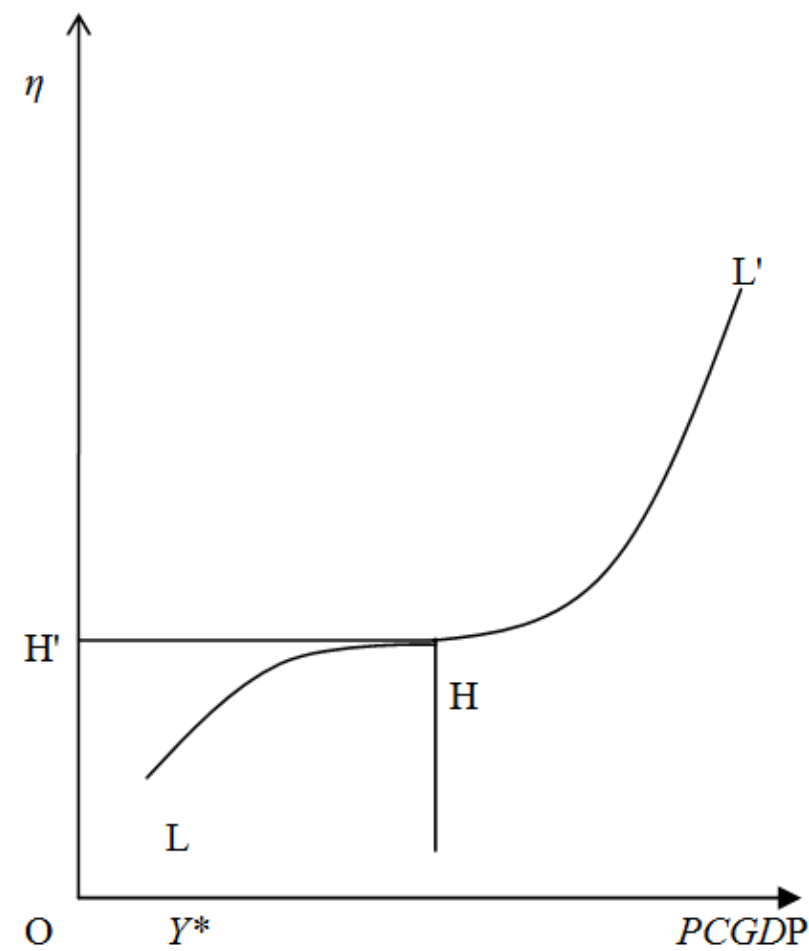

Fig. 2. The Dynamics of $\eta$ and the per capita GDP (PCGDP): Concave-convex relationship 
In the existing literature, the existence and consequences of nonlinearities between $\Omega$ and $Y$ did not arise as an important facet in the context of FDI and development. Ours is the first paper that shows the existence of nonlinearities in this context. As a result, prior studiesbased on linear, or log-linear, relationships-could have given incorrect conclusions. Secondly, we note interesting consequences of the nonlinearities: To the left of the trap $\left(Y^{*}\right)$, the change in the flow of $F D I$ as a percentage of GDP declines as the per capita GDP rises. To the right of the trap, the change in the flow of $F D I$ as a percentage of GDP rises with an increase in per capita $G D P$. Thus, in order to attract $F D I$, as our results show, the MENA countries must achieve a critical level of economic development in terms of the per capita GDPotherwise $F D I$ flows will be extremely sluggish. From the dataset available for 16 countries during 1996-2013, we find the per capita income trap is at US\$ 10,000 for MENA countries. Thirdly, we find the relationship between $\Omega$ and $Y$ to be inverse S-shaped: For per capita incomes less than $\$ 10,000$, the function is concave-as per capita $G D P$ rises, $F D I$ as a percentage of $G D P$ rises at a declining rate. Beyond this critical value of per capita $G D P$ (trap/separatrix), the function becomes convex: As per capita $G D P$ rises above the trap, $F D I$ as a percentage of $G D P$ then rises at an increasing rate.

It is important to note that nonlinearities are recognized as important characteristics of growth economics such that regression parameters are subject to various non-linear processes (Banerjee and Duflo, 2002; Durlauf et al., 2001; Maasoumi et al., 2007 among many). However, in our work, we have reversed the causality: We have chosen $F D I(\Omega)$ as the dependent variable and per capita $G D P(Y)$ as the independent variable to discover how $G D P$ and $G D P$ growth can create nonlinearities for $F D I$.

For emerging nations, in an early work, Campos (2002) noted that the inflows of FDI do not depend on $G D P$ or GDP growth once threshold effects are considered. Alfaro (2003) argued that the role of FDI and its attractiveness depends upon the specific sector where FDI flows take place. Sadni-Jallab et al. (2008) argue that there had been no interrelationships between $F D I$ flows and GDP variables for the MENA nations. Jyun-Yi and Chih-Chiang (2008) did not find any evidence for 67 nations during 1975-2000 that GDP variables and $F D I$ flows are interrelated. Thus, the past literature has not been able to pin down the specific interrelationships between $F D I$ flows and GDP variables. In this very work, we find evidence of non-linear relationships between $F D I$ flows and GDP variables after controlling for other important macroeconomic factors. Our findings can explain why the past literature did not find strong evidence of interrelationships since they postulated $(\log )$ linear functions. In the concluding section we explain our main findings.

\section{Conclusion}

The main empirical findings are two-fold: First, we find evidence that the $F D I$-to-GDP ratio in the MENA countries can be explained by the lagged values of the level of economic development measured by the per capita GDP. As expected, other macroeconomic and political variables have anticipated impacts on the FDI flows for the MENA countries. The exceptions are the following: (i) Purchasing Power Parity $(P P P)$ variable, whose impacts are uncertain, while (ii) the lagged value of $(\log ) G D P$ that does not seem to have any statistically significant effect on the $F D I$ flows in the MENA region. On the other hand, variables like inflation $(I N F)$, quality of political regime/governance $(P O L R)$, openness indicator $(O P E N)$, seem to accelerate the pace of $F D I$ mobility to the region. Though the size of population ( $L n P O P)$ seems to enhance the FDI flows, yet the statistical significance is not always observed.

Secondly, we also assess the non-linear impacts of economic development on the FDI flows to the region. We argue that the FDI flows are not a free lunch as the national governments must create suitable conditions to attract $F D I$ to their nations. As seen above, there are known factors that promote FDI flows. We also find empirical support to the plausible thesis that low levels of economic development of the receiving nation acts as a barrier to FDI flows. We also note that there is an automatic (correction) mechanism that improves the FDI flows to MENA countries only after a nation's per capita income reaches a threshold level $(\$ 10,000)$. Our paper is the first one to highlight the possibility of a developmental trap that increases the sluggishness of FDI to the MENA region. We show the existence of a threshold of per capita income $Y^{*}$ by using the $F D I$ and per capita income data from the MENA region. For $Y<Y^{*}(=10,000)$, an increase in per capita $G D P$ increases $F D I$ to $G D P$ ratio at a declining rate. We note that for $Y>Y^{*}$, interestingly, the impact of per capita $G D P$ on the $F D I$ flows undergoes a sea change: Any increase in per capita GDP above $Y^{*}$ increases the inflow of $F D I$-as $G D P$ rises-at an increasing rate. The implications of our findings are two-fold: First of all, we observe a complex and non-linear relationship between FDI flows $\left(X_{i t}\right)$ and per capita $G D P\left(Y_{i t}\right)$ in the MENA region. Our finding is novel and extremely significant in the context of economic development as we are able to show a virtuous relationship between economic development and FDI flows above the development trap $\left(Y^{*}\right)$. Thus, if MENA countries seek to enhance FDI flows, these countries must also unleash relevant economic policies to enhance their per capita income.

\section{Acknowledgement}

Authors are grateful to the anonymous referee and the editor for detailed comments. The usual disclaimer applies. 


\section{Funding Information}

Authors have received no funding from any source for this research.

\section{Author's Contributions}

Partha Gangopadhyay: Econometric modeling, writing the manuscript and results, theory.

Mohamed Elafif: Data set, econometric testing, literature review.

\section{Ethics}

The article is original and contains unpublished materials. The corresponding author confirms that all authors have read and approved the manuscript and no ethical issues involved.

\section{References}

Alfaro, L., 2003. FDI and Growth: Does the Sector Matter?" 1st Edn., Harvard Business School, Harvard University, Boston, pp: 32.

Banerjee, A.V. and E. Duflo, 2002. Inequality and growth: What can the data say?" J. Econom. Growth, 8: 267-300. DOI: $10.1023 / \mathrm{A}: 1026205114860$

Borensztein, E., J. De Gregorio and J.W. Lee, 1998. How does foreign direct investment affect economic growth? J. Int. Econom., 45: 115-135. DOI: $10.1016 / \mathrm{S} 0022-1996(97) 00033-0$

Campos, N., 2002. FDI as technology transferred: Some evidence from the emerging nations. Manchester School, 70: 398-412.
Durlauf, S., A. Kourtelos and A. Minkin, 2001. The local Solow growth model. Eur. Econom. Rev., 45: 928-940. DOI: 10.1016/S0014-2921(01)00120-9

EIU, 2015. World investment prospects to 2011: Foreign direct investment and the challenge of political risk. Economist's Intelligent Unit.

Jyun-Yi, W. and H. Chih-Chiang, 2008. Does foreign direct investment promote economic growth? Evidence from a threshold regression analysis. Econom. Bull., 15: 1-10.

Maasoumi, E., J. Racine and T. Stengos, 2007. Growth and convergence: A profile of distribution dynamics and mobility. J. Econom., 136: 483-508. DOI: $10.1016 / j$.jeconom.2005.11.012

O'Sullivan, A., M.E. Rey and J.G. Mendez, 2011. Opportunities and challenges in the MENA region. OECD Economics Department.

Onyeiwu, S., 2003. Analysis of FDI flows to developing countries: Is the MENA region different? Proceedings of the ERF 10th Annual Conference, (AC' 03), Marrakech, Morocco, 1-22.

Sadni-Jallab, M., M. Gbakou and R.P. Sandretto, 2008. Foreign direct investment, macroeconomic instability and economic growth in MENA countries. ATPC Work in Progress.

Ucal, M., K.M. Ozcan, M.H. Bilgin and J. Mungo, 2010. Relationship between financial crisis and foreign direct investment in developing countries using semiparametric regression approach. J. Bus. Econom. Manage., 11: 20-33. 